http://dx.doi.org/10.18232/alhe.939

Artículos

\title{
Desregulación de sectores estratégicos en contexto semiperiférico: las comunicaciones satelitales en Argentina, 1991-2006
}

\section{Deregulation of Strategic Sectors in a Semi-Peripheral Context: Satellite Communications in Argentina, 1991-2006}

\author{
Diego Hurtado $1, *$ (D) 0000-0002-4849-9790 \\ Natasa Loizou ${ }^{1,2}$ iD 0000-0002-4849-9790 \\ ${ }^{1}$ Universidad Nacional de San Martín, San Martín, Argentina. \\ ${ }^{2}$ Consejo Nacional de Investigaciones Científicas y Tecnológicas, Buenos Aires, Argentina. \\ *Correspondencia: dhurtado@unsam.edu.ar
}

Resumen. En 1994 fue creada Nahuelsat, la primera empresa de comunicaciones satelitales con base en Argentina y mayoría accionaria de capitales europeos. Reconstruimos a partir de fuentes primarias la trayectoria de Nahuelsat y analizamos su desempeño y las razones que llevaron a su colapso en 2006 como un caso de desempeño de una firma en un sector económicamente estratégico en un país semiperiférico. Encontramos que la privatización y desregulación de las comunicaciones satelitales, la incapacidad del Estado para influir en las "reglas de juego" globales, así como la falta de incentivos orientados a coordinar las actividades de Nahuelsat con la política espacial y a producir enraizamiento en el ecosistema económico local explican su inviabilidad, a pesar de las "señales" positivas del mercado regional. El análisis del proceso de toma de decisiones muestra la incompatibilidad entre la dinámica de las grandes corporaciones globales y las iniciativas de desregulación del sector.

CÓMO CITAR: Hurtado, D. y Loizou, N. (2019). Desregulación de sectores estratégicos en contexto semiperiférico: las comunicaciones satelitales en Argentina, 1991-2006. America Latina en la Historia Económica, 26(1), e939. DOI: 10.18232/alhe.939 
Palabras clave: comunicación satelital; neoliberalismo semiperiférico; sector estratégico; Nahuelsat.

Abstract. In 1994, Nahuelsat -the first satellite communication firm based in Argentina and European majority shareholders- was created. We reconstruct the Nahuelsat trajectory from primary sources and analyze its performance and the reasons leading to its collapse in 2006 as a case study of the performance of a firm within an economically strategic sector in a semi-peripheral country. We find that satellite communication privatization and deregulation, the State inability to influence the global "rules of the game", as well as the lack of incentives oriented to coordinate their activities with the Argentine space policy and to produce embeddedness in the local economic ecosystem help explain the unfeasibility of Nahuelsat, despite the very positive "signals" of the regional market. The analysis of the decision-making process shows the incompatibility between the dynamics of the global big corporations and the deregulation initiatives of the sector.

Key words: satellite communication; semi-peripheral neoliberalism; strategic industry; Nahuelsat.

JEL: L25; F23; N76; O25.

Recibido: 10 de diciembre de 2017.

Aceptado: 7 de mayo de 2018.

Publicado: 19 de julio de 2018

Organismos colaboradores: Universidad Nacional de San Martín; Consejo Nacional de Investigaciones Científicas y Tecnológicas; Agencia Nacional de Promoción Científica y Tecnológica del Ministerio de Ciencia, Tecnología e Innovación Productiva, Argentina.

\section{INTRODUCCIÓN}

La elaboración y ejecución de políticas industriales y tecnológicas -incluidas las actividades de investigación y desarrollo (en adelante I+D) y los servicios de alta tecnología-, así como su relación con el problema del cambio institucional integran la lista de las principales debilidades que enfrentan los países semiperiféricos para impulsar procesos de diversificación de la matriz productiva, industrialización y desarrollo económico 1 Las dinámicas económicas y políticas relacionadas con la producción y la circulación de mercancías o servicios en sectores de retornos crecientes deben enfrentar numerosos obstáculos propios de las economías semiperiféricas: la inestabilidad institucional que debilita la gestión y continuidad de las políticas públicas, la baja inversión en I+D local del sector privado, la presencia dominante de empresas trasnacionales en los sectores dinámicos, que aplican estrategias desconectadas de los ecosistemas económicos locales, la financiarización especulativa creciente, desde fines de la década de 1970, y la desventaja geopolítica para negociar las "reglas de juego" dominantes en el escenario global que hagan posible la construcción de capacidades organizacionales, regulatorias, tecnológicas, etcétera.

\footnotetext{
${ }^{1}$ Asumimos que la estructura del sistema mundial ha sido estable a lo largo de un periodo sustancial y que la semiperiferia no es un estadio de transición desde la periferia hacia el centro, sino uno permanente (Babones, 2005, p. 53). Sobre el concepto de semiperiferia, véanse Arrighi y Drangel (1986); Chase-Dunn (1998, pp. 210-214); Clark (2010) y Martin (1990). Uno de sus rasgos distintivos ha sido el desarrollo dependiente y, desde los años ochenta, la creciente dependencia del capital financiero (Evans, 1979, 1985, pp. 192-194). La evolución de las condicionalidades impuestas por el Consenso de Washington ha puesto limitaciones adicionales a las economías semiperiféricas en relación con el acceso al conocimiento (Chang, 2009, pp. 76-77; Deere 2009; Nguyen, 2010).
} 
Desde la perspectiva de las economías centrales, mientras que las aspiraciones de las economías semiperiféricas a ingresar en sectores de retornos crecientes son percibidas como potencialmente desestabilizadoras para el orden político y económico global, la venta de tecnología y la inversión extranjera directa en sectores dinámicos de la industria y de los servicios en los países semiperiféricos son componentes codiciados para ganar escala y alcance 2

Este artículo se enfoca en la política de comunicaciones satelitales de Argentina entre comienzos de la década de 1990 y los años que siguieron a la crisis económica terminal de 2001 . Se reconstruye y analiza la trayectoria de Nahuelsat, creada en 1994 como la primera empresa de comunicaciones satelitales de capitales extranjeros con base en Argentina, su intento por estabilizar una flota de dos satélites para ocupar las posiciones orbitales asignadas a Argentina por la Unión Internacional de Telecomunicaciones (en adelante UIT) -organismo dependiente de la Organización de Naciones Unidas- y, finalmente, las razones que motivaron su quiebra y su reemplazo por la empresa estatal Empresa Argentina de Soluciones Satelitales (en adelante ArSAT) en 2006.

Presentamos a Nahuelsat como ejemplo de un proceso de privatización y extranjerización de un sector económicamente estratégico en Argentina de los años noventa, impulsado por dos gestiones de gobierno -Carlos Menem (1989-1999) y Fernando de la Rúa (1999-2001)- quienes promovieron una variante de neoliberalismo con especificidades propias de los países semiperiféricos. Por tal motivo, vamos a caracterizar la ideología que orientó las políticas económicas de estos dos gobiernos a partir de la noción de neoliberalismo semiperiférico, cuyo rasgo distintivo es la subordinación geopolítica y geoeconómica al neoliberalismo de las economías centrales a través de la desregulación de flujos financieros y comerciales, el desmantelamiento de las políticas tecnológicas e industriales y la privatización de los sectores económicamente estratégicos además de la promoción de la inversión extranjera directa. Entre las consecuencias visibles de esta ideología, que el caso presentado confirma, son el impacto negativo sobre procesos de aprendizaje y escalamiento tecnológico y organizacional en sectores dinámicos, la destrucción de capacidades estatales de regulación, coordinación y gestión de políticas y la primarización y extranjerización de la economía 3

Nos proponemos indagar las limitaciones y contradicciones de la política de comunicaciones satelitales de estos dos gobiernos, que estuvo centrada en: $a$ ) impulsar la privatización y desregulación -entendida como franca desinstitucionalización- del sector a partir de esquemas de libre mercado incompatibles con la dinámica de las grandes corporaciones globales $4^{4} \mathrm{y}$, en este contexto, $b$ ) promover una empresa de comunicaciones satelitales con mayoría accionaria extranjera sin incentivos orientados a coordinar sus actividades con la política espacial o a producir iniciativas de enraizamiento en el ecosistema económico local. Con referencia a este último punto, veremos que Nahuelsat derivó en una estructura empresarial inviable que caracterizamos como enclave satelital.

\footnotetext{
${ }^{2}$ Para una discusión y estimación de los ingentes gastos públicos en importación de maquinarias y equipos en países en desarrollo, véase Yülek (2012, pp. 12-13).

${ }^{3}$ Sobre las políticas económicas de este periodo, véanse Azpiazu y Schorr (2010); Basualdo (2006) y Gaggero (2016).

${ }^{4}$ Hablamos de desinstitucionalización para enfatizar las consecuencias de una noción de desregulación concebida erróneamente como sinónimo de laissez faire o ausencia de control y, por lo tanto, de capacidades técnicas y burocráticas.
} 


\section{SECTORES ESTRATÉGICOS Y NEOLIBERALISMO SEMIPERIFÉRICO}

Las industrias globales de telecomunicaciones y satélites geoestacionarios experimentaron un crecimiento acelerado durante los años noventa. El aumento de la tasa de inversiones puso en tensión la participación de los gobiernos, especialmente en los países de las periferias. Mientras que un postulado de la ortodoxia era que este auge de inversiones debía ser incentivado por la libre circulación del capital, el hecho de que se tratara de un sector estratégico suponía la necesidad de marcos regulatorios que pudieran garantizar un grado razonable de estabilidad, previsibilidad y equidad para todos los actores económicos involucrados. Sin embargo, la creación de la Organización Mundial de Comercio en 1995 y el Acuerdo General sobre el Comercio de Servicios que entró en vigor ese mismo año, así como la propia dinámica de organismos como la UIT, donde las grandes corporaciones tienen voz en los procesos de toma de decisiones, dan cuenta de un entorno global orientado a debilitar los marcos regulatorios de las periferias en sectores de retornos crecientes (Lee, 1996; McCormick, 2013, p. 17).

En los países centrales, desde los años sesenta, la comunicación satelital ha sido objeto de políticas industriales y tecnológicas coordinadas. Debido a su alto contenido de $\mathrm{I}+\mathrm{D}$, los efectos de difusión de conocimiento técnico y su relevancia en el comercio internacional, los países centrales asumieron que sus gobiernos deben intervenir, apoyar y proteger este tipo de industrias ${ }_{5}^{5}$ Durante la siguiente década, estos países fueron capaces de impulsar procesos de cambio institucional y acumulación de capacidades enfocados en producir y gerenciar empresas de comunicación satelital y producción de satélites, mientras que en la década de 1990 la radicalización neoliberal puso en cuestión "la asistencia gubernamental a las industrias económicamente estratégicas [como] un importante punto de discordia en la arena política internacional" (Michalski, 1991, pp. 7-8). A grandes rasgos, los debates sobre esta cuestión fueron estabilizados por los organismos de gobernanza global a partir de un acuerdo tácito que se podría parafrasear con la siguiente fórmula: mientras que en las economías centrales los sectores estratégicos continuarían siendo objeto de apoyo activo del Estado - de forma manifiesta u oculta- ${ }^{6}$ en las periferias se comienza a ejercer -a través de mecanismos formales e informales- una fuerte presión para promover su desregulación. Uno de los rasgos definitorios de lo que llamamos neoliberalismo semiperiférico es justamente la desregulación de los sectores económicamente estratégicos, que se manifiesta en procesos de desinstitucionalización, entendidos como pérdida de capacidades estatales de gestión y coordinación de políticas tecnológicas e industriales, incluidas las actividades de I+D y los servicios de alta tecnología.

Consistente con esta orientación, algunos países de América Latina tendieron a ignorar las lecciones que surgen de las trayectorias de aprendizaje de las economías centrales, en particular el hecho de que los sectores estratégicos son de competencia imperfecta y presentan dentro de los países estructuras monopólicas y oligopólicas (Hartley, 2014, pp. 143, 151-153). En Argentina, los programas de ajuste estructural promovidos y financiados por el Banco Mundial -componentes

${ }^{5}$ Sobre el escenario global de las comunicaciones satelitales y su evolución, véanse Martin, Anderson y Bartamian (2007); McCormick (2013), y Pelton, Oslund y Marshall (2004).

${ }^{6}$ Algunos autores detallan cómo, mientras las grandes empresas estadunidenses dependen de los subsidios del gobierno de Estados Unidos, de un entorno regulatorio favorable, de apoyo a sus actividades de $\mathrm{I}^{+\mathrm{D}}$, de protección de la propiedad intelectual y respaldo en sus proyectos de inversión en otros países, por otro lado, todas estas transformaciones son invisibilizadas por un discurso de fundamentalismo de libre mercado. Etzkowitz, Levitt y Gulbrandsen, 2000, p. 685) explican que en este escenario dominan "políticas industriales de facto" y Block (2008) habla de "estado desarrollista oculto". 
cruciales de los mecanismos de subordinación del Estado a los intereses de las corporaciones (Corbalán, 2002, p. 167) - fueron acompañados por la actividad de los think tanks neoliberales para imponer un nuevo sentido común que tendió a subestimar las políticas industriales y tecnológicas, como anacrónicas. Así, de manera similar a otros países de la región, como México, Venezuela o Perú, en Argentina se impulsó la apertura del sector de las comunicaciones satelitales a corporaciones trasnacionales, así como la privatización y desregulación de los sistemas de comunicaciones, en contraste con países como Corea del Sur, Singapur o Malasia, donde las iniciativas de liberalización fueron restringidas (Schiller, 1999, p. 45).

Fue en ese contexto que, sin contar con las capacidades públicas necesarias ni con objetivos de mediano plazo capaces de responder a la creciente complejidad de las demandas sectoriales, el gobierno argentino comenzó a promover el negocio de las comunicaciones satelitales. Así, mientras que en 1991 se había creado la Comisión Nacional de Actividades Espaciales (ConAE) y se iniciaba un programa civil de desarrollo de satélites de observación, 7 en 1994, sin ningún tipo de coordinación o contacto con esta iniciativa, se crea Nahuelsat, la primera firma de comunicaciones satelitales con sede en Argentina y composición accionaria con mayoría extranjera. El proceso de toma de decisiones públicas para promover las comunicaciones satelitales se limitó a atraer inversión extranjera directa. Sin embargo, como veremos, estas iniciativas fueron insuficientes y, si bien las señales del mercado insinuaban un clima de negocios de euforia regional y proyecciones muy promisorias para el sector, esta empresa no logró cumplir las expectativas mínimas necesarias para su viabilidad y terminó declarándose en bancarrota en 2006 sin llegar a cumplir con objetivos mínimos, como la ocupación de las dos posiciones orbitales que la uit le había asignado a Argentina.

\section{NAHUElSAT Y LA FIEBRE DEL ORO SATELITAL}

Con la llegada de Carlos Menem a la presidencia en 1989 se comenzó a proyectar la creación de una empresa privada para responder a la demanda comercial de transmisión satelital que no era cubierta por Intelsat y Panamsat, las empresas proveedoras que operaban en Argentina. La idea era plantear un escenario de competencia con los dos operadores autorizados. En 1985, durante el gobierno de Raúl Alfonsín (1983-1989), se había comenzado a trabajar en la generación de las capacidades institucionales necesarias para instalar en Argentina sistemas de satélites geoestacionarios de comunicación. Ese mismo año se avanzó en un pliego de especificaciones y se logró que la UIT reservara para Argentina dos posiciones orbitales $-80^{\circ} \mathrm{O}$ y $85^{\circ} \mathrm{O}-$ con el plazo de seis años para ocuparlas con dos satélites 8 Sin embargo, recién en 1990, un grupo de militares de la Marina y académicos de la Facultad de Ingeniería de la Universidad de Buenos Aires y del Instituto Tecnológico de Buenos Aires conformaron lo que llamaron Comisión Académico-Universitaria para Asuntos Espaciales y se propusieron llegar al gobierno con la propuesta de impulsar un sistema geoestacionario de comunicaciones satelitales. El 2 de enero de 1991, Menem recibió a esta comisión y decidió avanzar (Domínguez, 2013) ${ }^{9}$

\footnotetext{
${ }^{7}$ Sobre el contexto geopolítico de alineamiento incondicional con Estados Unidos, clausura de un programa de desarrollo de tecnología de misil y creación de la ConAE, véase Hurtado (2010, pp. 199-201).

${ }^{8} \mathrm{El}$ término $80^{\circ} \mathrm{O}$ debe leerse 80 grados de longitud oeste. Sobre las reservas de las dos posiciones orbitales de $80^{\circ}$ O y $85^{\circ}$ O, véase Decreto 2061/1991.

${ }^{9}$ M. Pesado, entrevista personal realizada por Diego Hurtado, 30 de agosto de 2016.
} 
A comienzos de abril, se encomendó a la Comisión Nacional de Telecomunicaciones la elaboración de los pliegos de bases y condiciones para el llamado a concurso público ${ }^{10}$ El gobierno llamó a concurso público nacional e internacional para "la provisión, puesta en servicio y operación de un Sistema Satelital, en el Servicio Fijo por Satélite" 11 y en mayo de 1993 se adjudicó la licitación a una unión transitoria de empresas, integrada por Aerospatiale sin, Alcatel Espace, Alenia Spazio SpA, Deutsche Aerospace AG (más tarde Daimler-Benz Aerospace) y la Empresa Brasileña de Telecomunicaciones (Embratel) ${ }^{12}$ Para entonces, la uIT ya había aprobado dos extensiones de plazos en la coordinación asignada a Argentina de una única posición orbital en la posición $71.8^{\circ}$ O. La fecha límite de la segunda prórroga era junio de 1994. El sector de comunicaciones satelitales fue declarado de interés nacional y la ahora Comisión Nacional de Comunicaciones (GNC), dependiente de la Secretaría de Comunicaciones (en adelante SECOM) ${ }^{13}$ autorizó a la Unión Transitoria de Empresas a operar a través del sistema de Paracomsat, una firma argentina que había adquirido los satélites Anik C1 y Anik C2 ${ }^{14}$ Originalmente en manos de la empresa Telesat, estos satélites continuaron siendo operados por la empresa canadiense, aunque pasaron a formar parte del sistema bautizado Nahuel Transitorio y se renombraron Nahuel I y Nahuel II (Martin, Anderson y Bartamian, 2007, p. 268) ${ }^{15}$ En paralelo se comenzó a gestionar un sistema satelital permanente.

En diciembre de 1993, con base en la Unión Transitoria de Empresas, se creó la empresa Nahuelsat como un consorcio con mayoría accionaria europea bajo el liderazgo de la empresa alemana Daimler-Benz Aerospace, en sociedad con la francesa Aerospatiale y la italiana Alenia Spazio ${ }^{16}$ No había participación pública y la presencia de accionistas argentinos era menor a $30 \%$. Eckart Schober, ingeniero procedente de la Deutsche Aerospace, es nombrado gerente general de Nahuelsat. Más tarde, Schober (1996) explica que el hecho de haber montado el sistema provisorio Nahuel Transitorio para proveer servicios de forma inmediata en la banda Ku, con cobertura sobre Argentina, Chile, Paraguay, Uruguay y el sur de Brasil, "ha estimulado fuertemente el mercado y ha iniciado un agudo deseo a lo largo de toda la región por apoyar sistemas modernos de comunicación satelital" (Schober, 1996).

Nahuelsat recibió del Estado argentino una licencia por 24 años, que podía extenderse por seis años adicionales, para operar el sistema de telecomunicaciones satelitales de la posición orbital argentina de $71.8^{\circ} \mathrm{O}$ y las que pudieran sumarse en el futuro. La SECOM también garantizó a

${ }^{10}$ Decreto 549/1991.

${ }^{11}$ Decreto 2061/1991, modificado por Decreto 1321/1992 para introducir sugerencias sobre firmas satelitales nacionales y extranjeras.

${ }^{12}$ Decreto $153 / 1993$.

${ }^{13}$ Decreto $1095 / 1993$.

${ }^{14}$ En el Decreto 2501/1993, de exención de gravámenes, véanse los antecedentes citados.

${ }^{15}$ La venta de los satélites Anik C1 y C2 de Telesat a la empresa argentina Paracomsat, que operaba para la Unión Transitoria de Empresas ambos satélites, fue por 36000000 de dólares, cifra que incluía la venta de activos de $90 \%$ de los dos satélites, un contrato de cuatro años para los servicios de mantenimiento de la posición por Telesat, $10 \%$ de las acciones de Paracomsat para Telesat y los ingresos por rentas adicionales para el uso de las instalaciones de control de los satélites Anik C1 y C2 durante el periodo del contrato de mantenimiento de la posición (Canadian Radio-Television and Telecommunications Commission, 1997).

${ }^{16}$ La composición accionaria inicial de Nahuelsat era: Daimler-Benz Aerospace $11 \%$; Aerospatiale $10 \%$; Alenia Spazio $10 \%$; Richefore Satellite Holding Ltd. (Jersey, Channel Island) 17.5\%; Lampebank International (Luxembourg) $11.5 \%$; International Finance Corporation (World Bank Group) $5 \%$; Group of Banco de la Provincia (Argentina) $11.5 \%$; BI SA/Bemberg Group (Argentina) 11.5\%; Antel (Uruguay) 6.5\%, y Publicom S. A. (Argentina) $5.5 \%$. Véanse: En enero habrá conexiones (1996) y Oyarzábal (1997, p. 17). 
Nahuelsat que no se autorizarían nuevos satélites para operar en el mercado nacional hasta enero de 2004, salvo que existiera un acuerdo de reciprocidad con el país de la empresa interesada en prestar servicios en Argentina ${ }^{17}$ Firmas satelitales estadunidenses expresaron formalmente su disgusto en lo que interpretaban como una tendencia proteccionista y monopólica que favorecía a Nahuelsat. Schober defendía a su firma de la acusación explicando que "ganamos la licitación e invertimos mucho dinero a riesgo para cumplir con los requisitos del gobierno argentino, de quien exigimos la protección y los derechos que merecemos".18

Con un capital inicial de 20000000 de dólares, la empresa comenzó a avanzar en la compra del primer satélite y en su lanzamiento -con un costo estimado de entre 60000000 y 80000000 de dólares-, además del equipamiento y la construcción de una estación terrena. Además, se creó una estructura de financiamiento que le diera a Nahuelsat 100000000 de dólares como capital adicional. Finalmente, para cubrir los costos totales del proyecto, que se estimaban en 250000 000, la empresa obtuvo 150000000 de financiamiento de deuda (Schober, 1996) ${ }^{19}$ Schober explica que el gobierno no le proporcionaba apoyo material a Nahuelsat, sino que "la única ayuda que le ha dado es el establecimiento de algunas restricciones en el mercado", así como el compromiso de darle preferencia a Nahuelsat en las necesidades públicas. A cambio, Schober interpreta que, como empresa licenciataria, no sólo las metas temporales y los objetivos operacionales asumidos por Nahuelsat, como "la total cobertura de Argentina con igual potencia, cantidad y cualidad de la capacidad de transmisión, y un estricto plazo para la operación del sistema [eran formidables, sino que la empresa también] corría con todos los riesgos financieros y comerciales" (Schober, 1996).

A mediados de 1995, el imaginario del mundo de los negocios producía expresiones del tipo la fiebre del oro con referencia al mercado de televisión directa al hogar al sur de la frontera de Estados Unidos. Las empresas que competían a nivel global buscaban adquirir nuevos satélites para el mercado latinoamericano, estimado en 75000000 de personas. Nahuelsat figuraba como una de las primeras en entrar en el negocio latinoamericano de televisión directa al hogar, capaz de ofrecer capacidad provisoria a fines de 1994 a partir del satélite Nahuel C1, nombre oficial con que se había rebautizado el Anik C1 (Video Age International en The new Latin American gold rush, 1995) ${ }^{20}$ El Departamento de Comercio de Estados Unidos prestaba atención a la adquisición de $5.7 \%$ de Nahuelsat por Telecom Argentina y pronosticaba una fuerte demanda de servicios satelitales, no sólo dentro de Argentina, sino también del resto de los países del Mercosur ${ }^{21}$ así como demanda de equipamiento que podrían vender empresas estadunidenses (United States Department of Commerce, 1995).

En 1996 Germán Kammerath es nombrado abogado titular de la SEcom. En ese momento, el paquete financiero de Nahuelsat contemplaba una cobertura de seguro completa que incluía, además de la puesta en órbita del primer satélite, un segundo lanzamiento y la puesta en órbita de un satélite de reserva -que en ese momento estaba en construcción en Europa- en caso de que

\footnotetext{
${ }^{17}$ Decreto $1095 / 1993$.

${ }^{18}$ Argentine controversy (2001).

${ }^{19}$ Argentine controversy (2001).

${ }^{20}$ The new Latin American (1995).

${ }^{21}$ El Mercosur había sido creado en 1991 por el Tratado de Asunción y entró en vigencia en diciembre de 1994, a partir del Tratado de Ouro Preto. Sus miembros iniciales fueron Argentina, Brasil, Paraguay y Uruguay. Venezuela se incorporó en 2012 y Bolivia en 2015.
} 
fallara el primero. Créditos por más de 130000000 de dólares fueron provistos por la corporación financiera internacional y las agencias europeas de crédito para la exportación: COFACE (Francia), HERMES (Alemania) y SAGE (Italia) ${ }^{22}$ (Schober, 1996).

En junio, Nahuelsat inauguró la Estación de Telecomando, Telemetría y Control -luego llamada Estación Terrena de Control Satelital-, ubicada en Benavídez, el partido de Tigre (provincia de Buenos Aires) ${ }^{23}$ Alrededor de 35 técnicos e ingenieros argentinos, muchos capacitados en Alemania y Francia, se iban a encargar de las tareas de control del satélite. ${ }^{24} \mathrm{Al}$ mes siguiente, Paracomsat le transfirió a Nahuelsat su cartera de negocios y sus 40 clientes. A mediados de diciembre, Schober explica que, además de haberse avanzado en un sistema satelital con doce años de vida útil en órbita, se habían concretado convenios de reciprocidad comercial con las empresas Telecom (México) y Embratel (Brasil). A la cobertura de Argentina y de otros países de la región en banda Ku estas empresas sumaban las coberturas en Banda C de los satélites Solidaridad 1 y 2 contratados a la empresa mexicana Satélites Mexicanos, S. A. de C. V. (SAtmex) y el brasileño Brasilsat (Auditoría General de la Nación, 2003b, p. 14)25

En ese momento, Schober señaló también que ya se avanzaba sobre un segundo satélite que completaría la flota de Nahuelsat, que "solo demandaría 180000000 de dólares, incluyendo satélite, seguros y el lanzamiento", puesto que ya se disponía de la estación terrena y los recursos humanos. Con un satélite en órbita sería fácil encontrar financiamiento directo, "ya sea con un nuevo socio o saliendo a la Bolsa". Mientras se trataba de obtener de la UIT una segunda posición orbital para Argentina, Schober estima que "el Nahuel 2 estaría listo para ser lanzado en julio de 1997 si no se cambia el diseño' 26 (Schober, 1996). Retrospectivamente, en un intercambio con los autores de este artículo, Schober evalúa que la cooperación con las empresas brasileña y mexicana "parecía el único camino para asegurar a la Argentina un sistema doméstico en el futuro. [Además,] había probablemente una perspectiva, o al menos una visión para una cooperación latinoamericana, o incluso un sistema armonizado o fusionado" 27

Cumpliendo con el calendario programado y con el presupuesto previsto 28 el primer satélite de telecomunicaciones, el Nahuel 1A, fue lanzado desde Kourou (Guyana Francesa) el 30 de enero de 1997 con un cohete Ariane 44L para ocupar la posición argentina 71.8 $\mathrm{O}$. El 6 de febrero, el Nahuel 1A desplegó con éxito sus paneles solares y entró en servicio a fines de abril. Con el nuevo satélite en órbita, se devolvieron a Telesat los satélites Anik C1 y C2. Los clientes de los satélites Anik fueron transferidos al Nahuel 1A, mientras que Paracomsat, que en ese momento facturaba alrededor de 20000000 de dólares, se disolvió. El nuevo satélite iba a dar cobertura desde Tierra del Fuego hasta el sur de Estados Unidos con un haz para Argentina y sus países limítrofes, otro haz para Brasil y otro global para todos los países de América Latina. El lanzamiento del Nahuel 2 se proyectaba para 1998 (Méndez, 3 de febrero de 1997).

\footnotetext{
${ }^{22}$ En enero habrá conexiones (1996).

${ }^{23}$ La estación terrena contaba con un predio de 20000 metros cuadrados y 1500 metros cuadrados cubiertos.

${ }^{24}$ Nahuel 1 será lanzado (1996).

${ }^{25}$ En enero habrá conexiones (1996). El satélite Solidaridad 1 iba a salir de servicio a fines de agosto de 2000.

${ }^{26}$ En enero habrá conexiones (1996).

${ }^{27}$ Schober, Hurtado y Loizou (Comunicación personal vía correo electrónico, 7 de noviembre de 2016).

${ }^{28}$ Schober, Hurtado y Loizou (Comunicación personal vía correo electrónico, 7 de noviembre de 2016).
} 


\section{NAHUELSAT EN LA TELARAÑA DE LOS GRANDES JUGADORES}

Con un satélite en órbita y el Nahuel 2 en camino, Nahuelsat aparecía como un caso de éxito. En abril de 1997, Deutsche Aerospace AG (DASA) ofreció a Schober una posición en Alemania. La idea era que otro colega alemán lo reemplazara en la gerencia de Nahuelsat. Sin embargo, el candidato a reemplazarlo no acepto 0 electromecánico graduado en la Universidad de Buenos Aires, que desde 1985 había trabajado en Messerschmitt-Bölkow-Blohm y, desde su creación, era parte del equipo de marketing de Nahuelsat. Schober no estuvo de acuerdo "ni con la decisión per se, ni en la forma en que fue tomada". Por esta razón renunció a Deutsche Aerospace AG y en julio de 1997 fundo Creotel Comunicaciones y Satélites, S. A., una empresa consultora con sede en Buenos Aires ${ }^{30}$ En ese momento, un think tank argentino estimaba que un tercio de la inversión extranjera directa de Estados Unidos en Argentina para el periodo 1997-2004 -estimada en 2560 millones de dólares- sería destinada al sector de telecomunicaciones 31

$\mathrm{Al}$ poco tiempo de su llegada a Nahuelsat, Salzer vio con sorpresa que el gobierno le quitaba a Nahuelsat la exclusividad para transmitir en banda Ku en territorio argentino. El objeto era permitir la entrada apresurada de DirecTV al mercado local, que presionaba para transmitir el Mundial de Futbol 1998 que se iba a realizar en Francia. En junio de 1998, la Secom y la Federal Communication Commission (FCC) de Estados Unidos firmaron en Washington un acuerdo de reciprocidad para la apertura de los respectivos mercados satelitales (United States Department of State, 1998). La interpretación forzada y equívoca del concepto de reciprocidad perjudicaba los objetivos de Nahuelsat de avanzar con el desarrollo de capacidades técnicas y financieras en un entorno que, si bien suponía competencia, le diera cierta protección. Salzer se refirió a la inequidad del convenio de reciprocidad por tratarse de un acuerdo unilateral, puesto que los satélites de Nahuelsat solo tenían llegada a Florida, una zona de bajo interés comercial. Explicaba Salzer: "Al carecer de una posición orbital para los Estados Unidos, estamos fuera del convenio firmado" 32 El gerente general de Nahuelsat también aludía a factores estratégicos, variable que estaba ausente en el discurso del gobierno: "Recordemos que una posición orbital no es un tema comercial; un $[s i c]$ primera instancia es un tema de seguridad nacional, es una extensión del espacio territorial al espacio extraterrestre. Además, el acceso de la República Argentina de [sic] un bien de valor económico es el acceso de [sic] un bien de valor político y estratégico' 33 .

Ahora bien, la presión de Nahuelsat sobre la SЕсOM obligó a reabrir la negociación con Estados Unidos. La viabilidad de medio término de Nahuelsat se basaba en el acuerdo firmado con la GNC, cuyo objetivo era utilizar las posiciones orbitales argentinas. Si bien había sólo una cuando Nahuelsat fue creada, estaba comprometida una segunda posición orbital para Argentina. Por un lado, Nahuelsat reclamaba que se negociara la obtención de la coordinación de una posición orbital adicional, que haría posible el acceso al mercado estadunidense, mientras que, por otro lado, intentaba establecer que el acuerdo de reciprocidad se hiciera efectivo a partir del momento en que se dieran las condiciones de reciprocidad efectiva. La SECOM, la CNC y Nahuelsat retomaron la negociación con la FCG de Estados Unidos. A los pocos meses de la firma del acuerdo de reciprocidad,

${ }^{29}$ Schober, Hurtado y Loizou (Comunicación personal vía correo electrónico, 7 de noviembre de 2016).

${ }^{30}$ Schober, Hurtado y Loizou (Comunicación personal vía correo electrónico, 7 de noviembre de 2016).

31 "U.S. Firms Target Argentine Telecoms", Wall Street Journal, 14 de octubre de 1997, p. A16.

${ }^{32}$ Comenzó la guerra (1988).

${ }^{33}$ Salzer examina (1999).

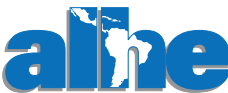


Estados Unidos ofreció a Argentina la posición orbital de $81^{\circ} \mathrm{O}$, desde la que se podría acceder al resto de los países de la región, pero sobre todo al territorio de América del norte (Belluscio, 21 de septiembre, 2015). Así, según lo acordado en Washington, la empresa estadunidense GE Americom había aceptado transferir la posición de $81^{\circ} \mathrm{O}$-que hasta ese momento gestionaba con permiso de la FCC - a Argentina (Salzer, 2016) Los plazos de entrada en vigencia del acuerdo de reciprocidad no se alteraron y DirecTV pudo entrar de inmediato al mercado argentino y transmitir el mundial de futbol 1998, mientras que Argentina ni siquiera había abierto la licitación para disponer de un satélite que pudiera ocupar la posición de $81^{\circ} \mathrm{O}$.

A fines de 1998, mientras se había iniciado la gestión ante la UIT para que se le asignara a Argentina la coordinación de la posición orbital de $81^{\circ} \mathrm{O}$ acordada en Washington, la SEcom decidió ceder la gestión de esta posición a Nahuelsat a cambio del compromiso de la empresa de ocuparla con el Nahuel 2 en los plazos fijados. Ahora bien, simultáneamente con el acuerdo de reciprocidad y el inicio de las gestiones por la posición de $81^{\circ} \mathrm{O}$, la empresa estadunidense GE Americom adquirió 28.75\% del paquete accionario de Nahuelsat (Auditoría General de la Nación, 2003a, p. 33). De esta forma, DirectTV entró al mercado local, GE Americom ganó una importante participación en Nahuelsat - conservando de esta forma su influencia sobre el acceso a la posición de $81^{\circ} \mathrm{O}-\mathrm{y}$, al año siguiente, Nahuelsat hacía público que debían diferir las decisiones relativas a avanzar en el segundo satélite Nahuel 2 hasta que mejoraran las economías de la región y cayeran las tasas de interés (Foley, 1999).

Sin embargo, a pesar de los problemas económicos de Brasil y Argentina, en ese momento América Latina era un mercado satelital codiciado. Si bien la devaluación de sus monedas tenía un impacto negativo sobre los negocios satelitales, este efecto era contrarrestado por el creciente tráfico de Internet y por la firme marcha hacia la desregulación que impulsaban los gobiernos de la región. El 25 \% del acceso a Internet en América Latina era por satélite, a diferencia de Europa, donde se alcanzaba $5 \%$ o en Estados Unidos, $0.5 \%$. En Argentina existían en ese momento 200000 usuarios sobre una población de 34000 000. Algunas proyecciones predecían que la capacidad de la banda Ku crecería a una tasa de 13 \% anual entre 1999 y 2005 en la región, pasando de 300 a 504 transpondedores (Foley, 1999) ${ }^{35}$

Mientras que las proyecciones sectoriales eran promisorias, las condiciones macroeconómicas se deterioraban y el ámbito en el que debía maniobrar Nahuelsat se complicaba. Salzer se quejaba de lo dificultoso y lento del proceso de licenciamiento necesario para ingresar al mercado estadunidense y de la marcada asimetría de los términos fijados por el acuerdo de reciprocidad respecto de las condiciones bajo las cuales Nahuelsat tenía que competir con su contraparte estadunidense, tanto en el mercado argentino como estadunidense. Al parecer, desregulación no significaba lo mismo para Argentina y Estados Unidos. El acuerdo permitía a Intelsat y Panamsat, que proveían servicios a Argentina en la banda Ku, expandirse a la banda C, así como la entrada a Argentina de otros operadores (Foley, 1999). El gobierno argentino respondía por canales informales que

\footnotetext{
${ }^{34}$ Resolución 2593 (27 de noviembre de 1998), SEcom. De acuerdo con el texto de esta resolución, en "los habituales procesos de coordinación bilateral de posiciones satelitales [llevados a cabo por la GNC y la FCC] los expertos de ambos países concluyeron la coordinación de una posición orbital en 81 grados longitud oeste con cobertura hemisférica norte y sur en Bandas C y Ku completas para la República Argentina, derivada de la original posición de $80^{\circ}$ establecida en los instrumentos de la licitación del sistema de satélite nacional multipropósito" (Schober, Hurtado y Loizou, Comunicación personal vía correo electrónico, 7 de noviembre de 2016).

${ }^{35}$ Los transpondedores (término del inglés transponder, que combina transmitter + responder) son los dispositivos que reciben, amplifican y retransmiten las señales de radiofrecuencia de los servicios de telecomunicaciones.
} 
Nahuelsat había perdido tiempo en el proceso de concesión de licencias o de adquisición del segundo satélite para ocupar la posición $81^{\circ} \mathrm{O}$, que le permitiría proyectar una señal sobre territorio estadunidense.

En ese momento, ya era claro que Argentina no disponía de una política con objetivos definidos y que sus capacidades de gestión y regulación eran vulnerables a las asimetrías propias del campo de fuerzas geopolítico. La debilidad del Estado argentino frente a presiones coordinadas del gobierno de Estados Unidos y las empresas estadunidenses puede considerarse un corolario de la política exterior del gobierno de Menem de alineamiento incondicional a la política exterior de Estados Unidos, fundada en la "aceptación realista del liderazgo estadunidense en el hemisferio occidental”. Esta perspectiva asumía que un "país periférico, empobrecido, endeudado y poco relevante para los intereses vitales de las potencias centrales [como Argentina, debía] bajar el nivel de sus confrontaciones políticas con las grandes potencias a prácticamente cero" (Escudé, 1992, pp. 20, 24, 31). En este caso, bajar el nivel de las confrontaciones significaba permitir la entrada inmediata de DirecTV en simultáneo a la compra de acciones de Nahuelsat por parte de GE Americom. Es decir, la geopolítica interfería con la libre competencia y la desregulación se limitaba a la pérdida de capacidades de maniobra del Estado argentino.

En febrero de 1999, sin un plan aparente de mediano plazo, la SECOM allanaba el terreno a la firma de acuerdos de reciprocidad mediante la adecuación de las condiciones de reciprocidad a los principios de la Organización Mundial de Comercio ${ }^{36}$ Ahora bien, en la medida en que el gobierno argentino cedía terreno, las potencias avanzaban. A fines de ese año, la Agencia de Radiocomunicaciones de Gran Bretaña sostenía que el satélite argentino que iba a ocupar la posición de $81^{\circ} \mathrm{O}$ podía causar niveles de interferencia inaceptables en la red satelital Inmarsat. La FCC de Estados Unidos también hacía un reclamo semejante y la SЕсом le respondía que había sido acordada con ella misma la posición $81^{\circ} \mathrm{O}$ y remitía a la FCC información de la ubicación de la estación terrena argentina (Auditoría General de la Nación, 2003a, p. 1).

El 10 de diciembre de 1999 Fernando de la Rúa asumió la presidencia en Argentina y el abogado Henoch Aguiar reemplazó a Kammerath al frente de la SEcom. Tres meses más tarde, dos empresas estadunidenses recibían la autorización de la FCG para acceder al Nahuel C -otro de los nombres con el que figura en algunos documentos el Nahuel 1A, por haber sido sucesor de los Anik C1 y C2- para proveer servicios a clientes estadunidenses. "Estas acciones representan otro paso en la implementación del compromiso de apertura del mercado de US a satélites licenciados por otros países", explicaba la autorización de la FCC (Tycz, 23 de marzo de 2000), aunque debe recordarse que GE Americom contaba con $28.75 \%$ de acciones en Nahuelsat.

El 4 de julio de 2000, una resolución de la Secretaría de Defensa de la Competencia y del Consumidor del Ministerio de Economía autorizaba la compra por parte de GE Capital Global Satellites de $11.5 \%$ de las acciones de Nahuelsat en posesión del Banco de la Provincia de Buenos Aires y $11.5 \%$ de BI SA/Bemberg Group. De esta forma, al $28.75 \%$ de las acciones que ya poseía la empresa estadunidense, sumaba $23 \%$ adicional. El mismo documento adjuntaba un informe de la Comisión Nacional de Defensa de la Competencia, que no ponía objeciones a esta compra de acciones "al no disminuir, restringir o distorsionar la competencia" y estimaba que la transacción iba a permitir a Nahuelsat "adquirir un segundo satélite que probablemente sea el satélite GE-6 [propiedad de GE Americom], que se lanzaría el segundo semestre de este año". Y explicaba: "La

\footnotetext{
36 “A través de la Resolución 3609” (19 de febrero de 1999), SЕсOм se incorporaban las nuevas condiciones al texto de la parte i del Reglamento de Gestión y Servicios Satelitales.
} 
progresiva toma de control de Nahuelsat por parte de GE Capital Global Satellites Inc., puede ser descripta como la estrategia de la última para extender su cobertura geográfica a la Argentina [...]"37 Habría que agregar que, además, ganaba la posición de $81^{\circ} \mathrm{O}$ para sumar acceso a los mercados regional y estadunidense. Dicho de otra forma, el supuesto libre mercado funcionaba de forma tal que la empresa estadunidense DirecTV había entrado al mercado argentino a cambio de que GE Americom -a través de su mayoría accionaria en Nahuelsat - entrara al mercado estadunidense con la posibilidad de utilizar un satélite de su propiedad en la posición de $81^{\circ} \mathrm{O}$ que había cedido en 1998 a Argentina. Así, el acuerdo de reciprocidad firmado en un contexto de desregulación terminó poniendo el mercado argentino de las comunicaciones satelitales en manos de empresas estadunidenses junto con la posición de $81^{\circ} \mathrm{O}$.

La CNC le informaba a la UIT que la fecha prevista para la ocupación de esta posición orbital era el 19 de octubre de 2003 (Auditoría General de la Nación, 2003a, p. 2). En agosto, Nahuelsat y GE Capital Global Satellites presentaron ante la SЕсом y la CNC una propuesta de inversión de aproximadamente 265000000 de dólares, que permitiría la adquisición por parte de Nahuelsat del satélite GE-6 -el grupo de General Electric proponía la venta de un satélite propio a la empresa en la que tenía mayoría accionaria- como el segundo satélite del sistema, que pasaría a llamarse Nahuel 2 (Auditoría General de la Nación, 2003a, p. 2). Sin embargo, el 6 de octubre, GE Capital Global Satellites retiró la propuesta de inversión ante la falta de acuerdo y aprobación de la SECOM y la CNC (Auditoría General de la Nación, 2003b, p. 21). Quince días más tarde, GE Americom puso en órbita el satélite GE-6, pero no ocupó la posición de $81^{\circ} \mathrm{O}$, sino que fue a la posición de $72^{\circ} \mathrm{O}$, junto al Nahuel $1 \mathrm{~A}$ (Tycz, 12 de octubre de 2000).

Mientras Nahuelsat volvía a punto cero con el proyecto del segundo satélite, un grupo de diputados de la oposición presentó un proyecto de resolución, a fines de septiembre de 2000, para pedir informes al poder ejecutivo por la adjudicación directa, apresurada y arbitraria, de la posición orbital de $81^{\circ} \mathrm{O}$ a Nahuelsat. Además de la omisión de la presentación del plan de negocios de la empresa, el proyecto parlamentario también hablaba de graves incumplimientos que ponían en riesgo "la utilización efectiva de la posición orbital de 81 Oeste" (Cámara de Diputados, 2000a). En la sesión plenaria de la Cámara de Diputados del 11 de noviembre se aprobó un proyecto de declaración que sostenía que esta cámara "vería con agrado que el poder ejecutivo, a través de los organismos que correspondan, arbitre los medios necesarios a fin de declarar la nulidad absoluta e insanable de la Resolución SC $\mathrm{N}^{\circ}$ 2.593/98", por la cual se le asignaba a Nahuelsat la órbita de $81^{\circ} \mathrm{O}$, y solicitaba "que disponga el pertinente llamado a concurso para la puesta en órbita de un satélite argentino en la posición orbital 81 O” (Cámara de Diputados, 2000b). Al margen de ambigüedades como la expresión un satélite argentino -sería preciso decir un satélite en la posición orbital coordinada por Argentina-, la batalla parlamentaria por la posición de $81^{\circ} \mathrm{O}$ iba a continuar hasta el final abrupto del gobierno de De la Rúa (Cámara de Diputados, 2001). Sin embargo, Nahuelsat conservaría esta posición hasta 2004, prolongando el incumplimiento de su ocupación y poniendo en peligro el compromiso argentino de su coordinación ante la UiT.

El poder ejecutivo no sólo ignoró esta reacción parlamentaria, sino que la SEcom puso en práctica la reglamentación que le facilitaba la firma de acuerdos de reciprocidad para concretar acuerdos con Canadá, México, España, Brasil y Holanda. En el periodo 2000-2001, el gobierno de De la Rúa autorizó la entrada al país de alrededor de 20 satélites extranjeros. Diez eran de la empresa Intelsat, tres de New Skies Satellites (hoy Societé Européenne des Satellites, SEs), tres de

37 “Resolución 98” (4 de julio de 2000), Secretaría de Defensa de la Competencia y del Consumidor. 
Southern Satelite Corporation (subsidiaria de Intelsat), uno de Telesat Canadá, uno de Hispasat y otro de Loral Cyberstar International. Respecto a la SES, por ejemplo, la iniciativa del gobierno hacía posible que esta empresa comenzara a proveer servicios en agosto de 2000 a través de sus satélites NSS-803, NSS-806 y NSS-7. En los considerandos de la resolución que autorizó los diez satélites de Intelsat, la SЕсOM remarcaba en 2001 que "es deber del gobierno nacional velar por el incremento de la oferta de servicios competitivos y la multiplicidad de actores en el mercado, de modo tal de beneficiar a los consumidores y clientes de todo el país" (Godoy, 2017, pp. 824-833; Krakowiak, 2016). A diferencia del neoliberalismo de las economías centrales, el neoliberalismo semiperiférico ahora consideraba que la única variable relevante en las comunicaciones satelitales era el precio de los servicios.

En enero de 2001, Nahuelsat llamó a concurso de ofertas para la construcción del segundo satélite. En julio, GE Americom vendió $23 \%$ de las acciones de Nahuelsat que había adquirido en julio de 2000 para volver a $28.75 \%$. A mediados de ese año, el diputado Pablo Fondevila explicaba que "el riesgo más grande es que se pierda esta órbita $\left[81^{\circ} \mathrm{O}\right]$, porque sabemos que hay grandes grupos de telecomunicaciones (General Electric, entre otros) muy interesados en quedarse con ella justamente por su cobertura continental" ${ }^{38}$ En julio, SES adquirió el restante $28.75 \%$ del paquete accionario de GE Americom en Nahuelsat (Abelson y Sugrue, 2001). A fin de aquel año, mientras la economía argentina se derrumbaba y caía en la crisis económica más profunda de su historia, GE Americom pasó a integrar el nuevo consorcio europeo-estadunidense SES Americom al ser comprada por SES Global por 4300 millones de dólares 39

El satélite GE-6 pasó a llamarse AMC-6 y siguió compartiendo la posición vecina al Nahuel 1A, cada uno operado por sus respectivos dueños. Mientras los consorcios estadunidense y europeo se asociaban para consolidar una posición global dominante, desde la perspectiva de Argentina, el proceso se presentaba como una ristra de calamidades. El libre mercado satelital argentino era un rígido ajedrez donde todas las piezas relevantes eran movidas coordinadamente por la FCC, DirecTV, GE Americom o SES Global. A este escenario se sumaba la renuncia del presidente Fernando de la Rúa, el 20 de diciembre de 2001, como consecuencia de una crisis política y económica terminal. Este parteaguas abría un ciclo de revisión de la política satelital.

\section{Postergación del Nahuel 2 E inViabilidad de Nahuelsat}

La crisis económica terminal de diciembre de 2001 y el default sobre su deuda externa llevaron a Argentina a una transición política desordenada. Entre la renuncia de De la Rúa y las elecciones democráticas de 2003 pasaron cuatro presidentes provisionales. Durante este periodo se abandonó el régimen de cambio fijo establecido once años antes por la Ley de Convertibilidad. Un nuevo régimen declaró la emergencia pública, fijó los precios y los aranceles en pesos argentinos de acuerdo con la relación de cambio uno a uno con el dólar estadunidense y autorizó al poder ejecutivo a renegociar los precios y tarifas según criterios de competitividad y distribución del ingreso. La devaluación de la moneda generó profundas transformaciones en la estructura de precios relativos que afectaron a todas las actividades económicas. El gobierno de transición de Eduardo Duhalde

\footnotetext{
38 "Problemas para Aguiar con nuevo satélite argentino”, Ámbito Financiero, 21 de junio de 2001, p. 10.

${ }^{39}$ En 2001, la Société Européenne des Satellites, S. A. -una firma con sede en Luxemburgo- pasó a llamarse SES Global. Hoy esta firma es el mayor operador en el mundo de las comunicaciones satelitales y un pionero tecnológico. Satellite unit (2001); SES Global finalise (2001).
} 
(2002-2003) se propuso un cambio de modelo económico que se centraría en los sectores productivos como eje de la recuperación, en lugar de las finanzas, el endeudamiento y las empresas privatizadas (Zícari, 2017, p. 37).

Argentina debió pedir prórroga ante la uit para conservar la posición de $81^{\circ} \mathrm{O}$, mientras intentaba concebir una estrategia que le permitiera ocupar esta posición con un satélite. A mediados de marzo de 2002, Salzer renunció a Nahuelsat para ocupar la vicepresidencia de la European Aeronautic Defense and Space Company (en adelante EADs) Space Services en Alemania y fue reemplazado por Jorge Irigoin, ingeniero electrónico del Instituto Tecnológico de Buenos Aires, que había trabajado 20 años en Siemens y venía de desempeñarse como director en el grupo Socma.40 Irigoin contaba algunos años más tarde que, a fines de 2001, se había ido de Socma "para asumir como gerente general de Nahuelsat, un operador satelital para toda América con sede en la Argentina que estaba en default". Y agregaba que este era "uno de los primeros casos de reestructuración de deuda de empresas privadas" (Bernadou, 2005).

Salzer e Irigoin se presentaron en conferencia de prensa para referirse al impacto de la pesificación decidida por el gobierno, "porque los contratos particulares que tenemos con nuestros clientes eran en dólares y fueron pesificados, pero las deudas continúan siendo en dólares" 4 Salzer señala que $85 \%$ de los costos de la empresa estaba en dólares, mientras que $70 \%$ de sus ingresos estaba en pesos. Por su parte, Irigoin explica que, de todas formas, la empresa mantendría la inversión de 300000000 de dólares a doce años, lo que iba a posibilitar la puesta en órbita del satélite Nahuel 2. "No nos amedrenta la situación actual y contamos con el pleno apoyo de los accionistas", concluye ${ }^{42}$ Si bien reconoce que había una sobreoferta de la capacidad de los sistemas satelitales, también explica que, en los próximos 30 a 40 meses, Nahuel 2 estaría en su posición orbital y que tendría como objetivo atender el mercado de Estados Unidos, México y América Central, con potencia en la banda Ku y C.

No obstante, durante el periodo del gobierno de transición no se logró estabilizar la situación crítica de Nahuelsat ni diseñar una solución para el Nahuel 2. En este punto, la ocupación de la posición de $81^{\circ} \mathrm{O}$ no estaba garantizada. En 2003, un informe elaborado por la Auditoría General de la Nación que intentaba clarificar el desempeño de Nahuelsat a cargo de la CNC y la SECOM en especial, en lo referido a las previsiones para ocupar la segunda posición orbital-, mostraba la composición accionaria de Nahuelsat (véase cuadro 1).

En este mismo informe se habla del accionar difuso de la SEcom y de la cNC, que intimaron tardíamente a Nahuelsat para que presente un plan de actividades para ocupar la segunda posición orbital. Se identificó como una falencia institucional que Nahuelsat no hubiera coordinado sus acciones con la CONAE, ni en relación con asistencia técnica para determinar las características del Nahuel 2, ni con los lineamientos del Plan Espacial 1997-2008 vigente en ese momento. Es decir, en Argentina había un plan espacial que la SЕсOM había ignorado. El peligro de perder la posición de $81^{\circ} \mathrm{O}$ ponía de manifiesto estas inconsistencias. Si se consideraba que Nahuelsat había informado que el plazo promedio de construcción de un satélite era de 27.5 meses, entonces la fecha prevista y comunicada a la uIT para la puesta en órbita de Nahuel 2 -el 19 de octubre de 2003- estaba comprometida, puesto que el proceso de adquisición del satélite, según información provista por Nahuelsat en noviembre de 2001, se encontraba en el estadio del análisis de las tres

\footnotetext{
${ }^{40}$ Sociedad Macri (SocmA), uno de los mayores grupos económicos de Argentina liderado por la familia Macri.

${ }^{41}$ Quieren saber (2002).

${ }^{42}$ Se mantiene una inversión (2002).
} 


\section{CUADRO 1. COMPOSICIÓN ACGIONARIA DE NAHUELSAT EN 2003}

\begin{tabular}{lcc}
\hline Accionistas & Capital (dólares) & Porcentaje accionario \\
\hline Alenia Spazio & 10000000 & 10 \\
EADS Deutschland & 44000000 & 44 \\
Publicom & 5750000 & 5.75 \\
SES Global, SouthAmerica & 28750000 & 28.75 \\
Antel & 6500000 & 6.5 \\
Total & 95 & 95 \\
Corporación financiera internacional (accionista ausente) & 5000000 & 5 \\
\hline
\end{tabular}

Fuente: Auditoría General de la Nación (2003b).

ofertas que habían sido seleccionados de un grupo inicial de cinco fabricantes. Tampoco había evidencia de que la SECOM y la CNC hubieran intimado a Nahuelsat para que implementara un sistema transitorio (Auditoría General de la Nación, 2003b, pp. 15, 19, 20).

Finalmente, el proceso de auditoría también detectaba un estado de endeudamiento financiero al cierre de 2000 que podía poner en riesgo el cumplimiento de los planes para la puesta en órbita del segundo satélite. Ahora bien, la CNC no había realizado ninguna auditoría entre fines de 1998 y fines de 2001, no se había expedido sobre los cambios en la composición accionaria de Nahuelsat y desconocía la situación patrimonial y financiera de la empresa. Es decir, la cNc carecía de la posibilidad de evaluar la capacidad financiera de Nahuelsat para cumplir los compromisos asumidos. Se recomendaba volver a pedir una prórroga a la uIT para conservar la posición $81^{\circ} \mathrm{O}$ y asegurar la asistencia técnica de la ConAe (Auditoría General de la Nación, 2003b, pp. 24, 27, $31)$.

\section{Fin de Nahuelsat y GReAción de Arsat}

En mayo de 2003 Néstor Kirchner asumió la presidencia. En ese momento, la deuda pública era de 138 mil millones de dólares $-100 \%$ del PBI de Argentina-, la estructura del Estado se encontraba devastada, la inflación anual era mayor a $20 \%$, el índice de pobreza superaba $60 \%$ y el desempleo, $18 \%$. Este gobierno se propuso desde el comienzo recuperar las capacidades del Estado para comenzar a impulsar un nuevo ciclo de industrialización (Kulfas, 2016). El nuevo gobierno nombró a Guillermo Moreno al frente de la Secretaría de Comunicaciones y, a partir de ese momento, las comunicaciones satelitales fueron consideradas sector estratégico. Durante la década de 1990, ahora se criticaba, el sector había sido reducido a regulador administrativo del sector privado, "sin tener ninguna injerencia en la planificación federal y el diseño territorial de las políticas de Estado” (Vido y Bernal, 2015, p. 751).

En 2004, Nahuelsat enfrentó un escenario desfavorable. Su situación financiera era crítica, el proyecto Nahuel 2 no avanzaba y la posición orbital estaba en peligro de perderse. En abril, la Sесом comenzó a exigirle a Nahuelsat la búsqueda de nuevos socios para lograr $50 \%$ de inversiones necesarias -alrededor de 150000000 de dólares- para la construcción y el lanzamiento del segundo satélite. Mientras tanto, la SEcom y Nahuelsat fueron capaces de obtener de la UIT una extensión de la prórroga para ocupar la posición de $81^{\circ} \mathrm{O}$. La nueva fecha era octubre de 2005 . Nahuelsat había logrado reestructurar su deuda de 70000000 de dólares a través de acuerdos 
con bancos europeos y, menos de $20 \%$, con la corporación financiera internacional. Varias posibilidades fueron consideradas para obtener las inversiones: $a$ ) la apertura a la Bolsa de una parte del capital de Nahuelsat (véase cuadro 2); b) la apertura del capital del satélite Nahuel 2, que funcionaría como una nueva sociedad, y $c$ ) la emisión de obligaciones negociables. También se hablaba de contratar provisoriamente un satélite sustituto 43

Como resultado de la confrontación entre la SECOM y Nahuelsat, en junio de 2004 renunció Irigoin y el cargo de gerente general de Nahuelsat fue ocupado por el contador público Hernán Pflaum. A mediados de agosto, frente a la falta de señales claras de la empresa, el gobierno decidió revocar, por razones de ilegitimidad, la concesión de la coordinación de la posición de $81^{\circ}$ $\mathrm{O}$ y de las bandas de frecuencias asociadas otorgada a Nahuelsat ${ }^{44} \mathrm{Si}$ bien la firma podría continuar operando el Nahuel 1A, sus representantes argumentaron ante el gobierno que el retiro de la concesión dejaba a Nahuelsat sin la posibilidad de contar con una flota de satélites que asegurara la competitividad y viabilidad de la empresa ${ }^{45}$ En julio de 2005, Kirchner se reunió en la Casa Rosada con un grupo de empresarios para comunicarles que pensaba conformar la Empresa Argentina de Soluciones Satelitales (ARSAT), que se iba a encargar de construir, lanzar y operar un satélite a un costo estimado de 250000000 de dólares 46

Después de negociaciones reservadas entre el gobierno e Investigación Aplicada (INVAP), principal empresa pública de tecnología con sede en la provincia de Río Negro, la filosofía y la orientación de la política de comunicación satelital dio un giro decisivo: el gobierno le proponía a INVAP que se encargara del diseño y construcción de dos satélites geoestacionarios. El primero debía estar listo en el periodo 2007-2009 para ocupar la posición $81^{\circ} \mathrm{O}$. La fabricación y la puesta en órbita costaría 150000000 de dólares y su desarrollo -diseño y plan de producción- se estimaba en 30 000000 de dólares ${ }^{47}$ Además, la SECOM exploró la posibilidad de que los satélites fueran puestos en órbita por China y que algunas firmas del gigante asiático pudieran ser proveedoras de INVAP. El principal activo de ARsAT era la posición orbital de $81^{\circ}$ O. La SEcom estimaba que, cuando el primer satélite trabajara a plena capacidad, la explotación comercial de esa posición podría representar 90000000 de dólares anuales de ingresos 48 A comienzos de agosto de 2005, la SEcom explicaba que el gobierno no se proponía sólo la explotación comercial de la posición orbital, sino también promover la industria de fabricación de satélites 49

Ahora bien, mientras se avanzaba en estos planes era necesario ocupar la posición de $81^{\circ} \mathrm{O}$ antes del 19 de octubre de 2005. Con este fin se alquiló a Venezuela el satélite Anik E2, de la empresa Telesat, por 2100000 dólares. Era un satélite puesto en órbita en 1991, que ocupaba la posición de $67^{\circ} \mathrm{O}$ y que una tormenta solar averió en enero de 1994 (Lam, Boteler, Burlton y Evans, 2012). Este satélite ocupó la posición en el límite de la prórroga otorgada por la UIT, pero al llegar a la posición de $81^{\circ} \mathrm{O}$ su combustible se agotó en 20 días y dejó de operar el 23 de noviembre. En medio de estas contingencias, el gobierno argentino demoró la decisión sobre la posición orbital, no a través de una prórroga formal, sino a través de una prórroga de hecho, puesto

${ }^{43}$ El Nahuel II buscaría (2004); Nahuelsat quiere participar (2006); El Estado, a punto de controlar (2006).

${ }^{44}$ Resolución 188, 17 de agosto 2004, SECOM.

${ }^{45}$ Argentine Government (2004).

${ }^{46}$ El Estado le quitó (2004); Kirchner creará por ley (2005).

${ }^{47}$ INVAP sostuvo que diseñaría y construiría dos satélites con características similares al Nahuel 1A, con un peso de alrededor de 2000 kilogramos y capacidad de combustible para quince años (El Estado le quitó, 2004).

${ }^{48}$ Pekín también (2004); "El Gobierno ya asignó” (7 de junio de 2006).

${ }^{49}$ Nahuelsat quiere (2006). 
CUADRO 2. GOMPOSICIÓN ACGIONARIA DE NAHUELSAT EN 2004

\begin{tabular}{lc}
\hline Accionistas & Porcentaje accionario \\
\hline EADS Deutchelanz GMBH & 47.33 \\
Finmeccanica & 11.67 \\
Publicom & 5.75 \\
SES Global-South America Inc. & 28.75 \\
Antel & 6.5 \\
Total & 100 \\
\hline
\end{tabular}

Fuente: elaboración propia con base en El Nahuel II buscaría, 6 de abril de 2004; El Estado, a punto de controlar (2006).*

*En noviembre de 1998 se habían fusionado Daimler-Benz Aerospace y Chrysler Corporation para formar Daimler Chrysler Aerospace y, en julio de 2000, este grupo a su vez se fusionó con Aérospatiale-Matra de Francia y Construcciones Aeronáuticas de España para crear la EADS.

que la uit decidió difundir de manera definitiva en la conferencia mundial que el organismo la realizaría en 2007. En febrero de 2006, Gran Bretaña solicitó a la UIT que se le quitara a Argentina la coordinación de la posición de $81^{\circ} \mathrm{O}$ alegando que el satélite Anik E2 sufrió problemas técnicos serios y no trasmitía ninguna señal. La uit rechazó el reclamo británico ${ }^{50}$ A comienzos de abril de 2006, la Cámara de Diputados sancionó finalmente la Ley 26.092 por la cual se creó la empresa ARsat y se le otorgó el uso de la posición orbital de $81^{\circ} \mathrm{O}$ y de las frecuencias asociadas $\sqrt{51}$

Por su parte, el gerente general de Nahuelsat sostenía en un diario local que se deberían armonizar los proyectos de ARSAT y Nahuelsat, puesto que no existía espacio en el mercado para ambas compañías ${ }^{52}$ El 22 de mayo el gobierno oficializó la creación de ARSAT. Si bien, en paralelo, Nahuelsat intentaba recomponer su situación frente al gobierno nacional, a fines de octubre, Moreno negociaba con los accionistas de Nahuelsat el pase de los activos de esta empresa a ARSAT sin ningún costo. Se pretendía evitar la transferencia de pasivos al Estado, estimados en 32000 000 de dólares a comienzos de 2006. En ese momento la composición accionaria de Nahuelsat era $66.66 \%$ propiedad del consorcio EADS y $33.33 \%$ de la italiana Finmeccanica 53

En simultáneo, ARSAT realizó un llamado a ofertas entre ocho operadores satelitales para asegurar la continuidad de los servicios a los clientes del Nahuel $1 \mathrm{~A}$-puesto que restaba poco tiempo para finalizar su vida útil- y para colocar un satélite en la posición de $81^{\circ} \mathrm{O}$. La empresa seleccionada fue SES Global, que contaba con el AMC 6 en posición orbital vecina al Nahuel $1 \mathrm{~A} .5$

${ }^{50}$ P. P. Sat 1 occupies (2005); Puja con el Reino Unido (2006); Nahuelsat quiere (2006).

${ }^{51}$ J. Giglio, “Cambio de funciones entre Salas y Moreno”, La Nación, 13 de abril de 2006.

${ }^{52}$ Nahuelsat quiere (2006).

${ }^{53} \mathrm{El}$ Estado, a punto de controlar (2006).

${ }^{54}$ Se utilizaron del AMC 6 cuatro transpondedores en banda Ku extendida y tres en banda Ku estándar. 
En octubre se aceleró el proceso de integración de transferencias de los activos de Nahuelsat a Arsat. Finalmente, se firmaron dos cartas de intención entre las dos empresas. A través de la primera, Nahuelsat le transfería a ARsat el Nahuel 1A, la estación terrestre y la posición orbital $71.8^{\circ}$ O. A través de la segunda carta dejaba en manos de ARsat las acciones de Nahuelsat por el valor simbólico de un peso. El Estado se hacía cargo de las contingencias 55

\section{EPÍLOGO Y CONCLUSIONES}

El desempeño de la empresa Nahuelsat es representativo de los primeros pasos de un país semiperiférico en un sector de servicios tecnológicos de retornos crecientes considerado estratégico por las economías centrales y, por lo tanto, de estructura oligopólica. Las iniciativas de apertura del sector de las comunicaciones satelitales pusieron de manifiesto las inconsistencias que surgen al negar la función del Estado en los sectores estratégicos. En los hechos, las iniciativas de reducción de los umbrales de control y la ausencia de planes a mediano plazo -como versión degradada de lo que entiende por desregulación la ideología que hemos caracterizado como neoliberalismo semiperiférico- no sólo distorsionaron las condiciones de competencia (que en la retórica se sostenía que se buscaban favorecer), sino que además terminaron por fortalecer los determinantes geopolíticos que potenciaron las posiciones dominantes de los grandes corporaciones globales del sector. En este contexto de desinstitucionalización, la desconexión entre los objetivos de Nahuelsat y la política espacial definida en el ámbito de la CONAE, así como la ausencia de iniciativas de enraizamiento de la empresa en el ecosistema económico local, ayudan a entender que Nahuelsat haya tendido hacia una estructura de enclave satelital. En conjunto, esta posición demostró su vulnerabilidad al dejar a Nahuelsat a merced de intereses contradictorios que fueron generando las condiciones de su inviabilidad.

El empleo ficticio de la noción de reciprocidad llevó al Estado argentino a alterar unilateralmente el acuerdo original entre la SEcom y Nahuelsat y a transgredir las condiciones acordadas. Una vez que una interpretación asimétrica muy desventajosa de la reciprocidad entre Argentina y Estados Unidos hizo posible acordar la entrada apresurada de la empresa DirecTV al mercado local, se inició el proceso de erosión de Nahuelsat, a pesar de las supuestas señales muy positivas del mercado regional. Así, mientras que Nahuelsat no tenía forma de acceder al mercado de servicios satelitales estadunidenses, la empresa DirecTV entró al mercado argentino para transmitir el mundial de futbol de 1998. A su vez, la sesión de Estados Unidos a Argentina de la posición de $81^{\circ} \mathrm{O}$ inició un proceso confuso por el cual la empresa estadunidense GE Americom incrementó su participación accionaria en Nahuelsat, mientras negociaba la ubicación de un satélite propio en la posición de $81^{\circ} \mathrm{O}$ para prestar servicios en el mercado estadunidense. Es decir, el paquete accionario de Nahuelsat y la posición orbital de $81^{\circ} \mathrm{O}$ se transformaron en un campo de disputas, donde dos empresas estadunidenses -DirecTV y GE Americom- y el Estado estadunidense intervinieron de manera coordinada, obstaculizando los objetivos originales de Nahuelsat y poniendo en evidencia la ausencia de una política de comunicación satelital argentina con objetivos a mediano plazo. En definitiva, Nahuelsat nunca logró ocupar la posición de $81^{\circ} \mathrm{O}$. En paralelo, los permisos de entrada discrecional de satélites extranjeros al mercado local, que comenzó a conce-

\footnotetext{
${ }^{55}$ El Estado, a punto de controlar (2006); Naishtat, "Por un peso, el Estado se hará cargo de Nahuelsat”, El Clarín, 24 de octubre de 2006.
} 
der la SЕсOM a partir de mediados de 2000, volvieron a cambiar las "reglas de juego" y derivaron en la franca decadencia de la primera empresa de comunicación satelital con base en Argentina, en la que el gobierno de Menem había puesto las esperanzas de liderazgo regional.

Si se considera que para las economías centrales las posiciones orbitales representan una extensión de la soberanía territorial al espacio exterior, en el caso de un sector económicamente estratégico como las comunicaciones satelitales, las nociones de soberanía y negocios aparecen como complementarias y simbióticas: la viabilidad de los negocios sólo es posible mediante la afirmación de la soberanía, entendida en este caso como la capacidad de tomar decisiones autónomas sobre los activos del Estado. Sin embargo, desde la perspectiva del neoliberalismo semiperiférico no existen sectores estratégicos y, por lo tanto, la noción de soberanía carece de sentido frente a una noción de negocios que considera a los satélites como mercancías y que supone la única variable relevante de los servicios satelitales, por lo menos en la retórica, es el precio que deben pagar los consumidores. En este sentido, el fracaso de la empresa Nahuelsat aporta evidencia a favor de la inviabilidad económica del neoliberalismo semiperiférico, que termina actuando como fuerza periferizadora de esas economías.

La orientación económica industrialista y desarrollista del nuevo gobierno que se inició en 2003 llevó a reformular drásticamente la gestión del sector de comunicaciones satelitales bajo el liderazgo del Estado. La decisión de quitarle a Nahuelsat la gestión de la posición $81^{\circ} \mathrm{O}$ y de crear la empresa estatal ARSAT terminaron de sellar la quiebra de Nahuelsat. De esta forma, el proyecto neoliberal de crear una gran empresa de comunicaciones satelitales con mayoría accionaria de capitales extranjeros y la desregulación del sector de comunicaciones satelitales terminaba como un gran fracaso, ponía en peligro la coordinación argentina de la posición de $81^{\circ} \mathrm{O}$ y obligaba al Estado a intervenir y a hacerse cargo del sector.

Escapa a los objetivos de esta investigación el estudio de la trayectoria indudablemente exitosa de ARsAT que, entre otros hitos, logró ocupar las dos posiciones orbitales asignadas a Argentina por la UIT con satélites geoestacionarios diseñados y fabricados por empresas nacionales ${ }^{56}$ Sin embargo, la relevancia de la historia que hemos analizado en estas páginas es de absoluta actualidad si se considera que, en diciembre de 2015, asumió en Argentina un gobierno que retoma los principios del neoliberalismo semiperiférico y reinicia un proceso de desregulación del sector de las comunicaciones satelitales. Al cabo de dos años de gestión de este gobierno se manifiesta nuevamente la degradación de capacidades públicas de gestión y la coordinación de políticas. Sus primeras medidas fueron la contratación de la consultora estadunidense McKinsey para que redefiniera el plan de negocios de ARSAT y la paralización de la fabricación del tercer satélite argentino, violando una ley de promoción de la industria satelital aprobada por el Congreso en 2015. Hasta el momento del cierre de este artículo (febrero de 2018) se había permitido la entrada de 24 satélites extranjeros a partir de acuerdos ficticios de reciprocidad y se había intentado avanzar en un acuerdo secreto entre ARsat y la empresa estadunidense Hughes para crear una empresa compartida, pero con mayoría accionaria en manos de Hughes. La filtración de la carta de intención, publicada por un diario argentino, ha paralizado esta iniciativa hasta la fecha 57

\footnotetext{
${ }^{56}$ Para una aproximación a la trayectoria de la empresa ARsat, véanse Bianchi y Rus (2016); Hurtado, Bianchi y Lawler (2017).

${ }^{57}$ Para una evaluación periodística de este escenario, véase Hurtado (21 de julio de 2017).
} 
La dramática ironía de ver que retornan los dogmas y las iniciativas -junto con los nombres de algunos funcionarios- que mostraron su inviabilidad en la década de 1990 fue la principal motivación del presente artículo.

\section{REFERENCIAS}

Abelson, D. y Sugrue, T. (2 de octubre, 2001). Re-Application of General Electric Capital Corporation, Transferors, and, SES GLOBAL, S. A. [Order and Authorization No. DA 01-2100]. Estados Unidos: US Federal Communications Commission.

Argentine Controversy First Telecommunications Satellite (21 de diciembre, 2001). Recuperado dehttp://en.tvyvideo.com/200112214069/noticias/empresas/controversia-sobre-primer-satteargentino-de-telecomunicaciones.html

Argentine Government took second orbital position from Nahuelsat (18 de agosto, 2004). Recuperado de http://www.convergencialatina.com/News-Detail/61909-3-51

Arrighi, G. y Drangel, J. (1986). The stratification of the world-economy: An exploration of the semiperipheral zone. Review (Fernand Braudel Center), 10(1), 9-74.

Auditoría General de la Nación (2003a). Anexo I de la actuación 268/01 del Informe de auditoría de la Comisión Nacional de Telecomunicaciones (No. Actuación AGN 268/01). Buenos Aires: Departamento de Control del Sector Comunicaciones.

Auditoría General de la Nación (2003b). Informe de auditoría de la Comisión Nacional de Telecomunicaciones (No. Actuación AGN 268/01). Buenos Aires: Departamento de Control del Sector Comunicaciones.

Azpiazu, D. y Schorr, M. (2010). Hecho en Argentina: industria y economía, 1976-2007. Buenos Aires: Siglo XXI Editores.

Babones, S. (2005). The Country-Level Income Structure of the World-Economy. Journal of World-Systems Research, 11(1), 29-55. DOI: 10.5195/JWSR.2005.392

Basualdo, E. (2006). Estudios de historia económica argentina. Desde mediados del siglo XX a la actualidad. Argentina: Siglo XXI.

Belluscio, A. (21 de septiembre, 2015). Arsat-2: Argentina consolidates as Latin American satellite leader. Recuperado de http://www.nasaspaceflight.com

Bernadou, F. (24 de mayo, 2005). Motivar es inspirar las ganas de encarar nuevos desafíos. Recuperado de http://www.iprofesional.com

Bianchi, M. y Rus, G. (eds.). (2016). Plan Satelital Geoestacionario Argentino 2015-2035: el futuro llegó: Ley 27.208: desarrollo de la industria satelital. Buenos Aires: Oink.

Block, F. (2008). Swimming against the current: The rise of a hidden developmental State in the United States. Politics \& Society, 36(2), 169-206. DoI: 10.1177/0032329208318731

Cámara de Diputados (2000a). Proyecto de resolución. Periodo 118-28/09/2000 (TP 144)-6225D00. Argentina: Autor.

Cámara de Diputados (2000b). Sesión plenaria del día 30 de noviembre. Orden del Día 1439. Expediente 6225-D-00. Argentina: Autor.

Cámara de Diputados. Argentina (2001). Sesiones ordinarias del 15 de agosto. Orden del día 2759. Comisión de Comunicaciones e Informática. Argentina: Autor.

Canadian Radio-Television and Telecommunications Commission (18 de diciembre, 1997). Telecom decision CRTC 97-17 (5.1 Anik C1 and C2 Sale Proceeds 99; 5.2 Repurchase of Anik C1 106). Recuperado de http://www.crtc.gc.ca 
Chang, H. J. (2009). Bad samaritans: the myth of free trade and the secret history of capitalism. Nueva York: Bloomsbury Press.

Chase-Dunn, C. K. (1998). Global formation: structures of the world-economy, updated edition. Oxford: Rowman \& Littlefield Publishers.

Clark, R. (2010). World-System Mobility and Economic Growth, 1980-2000. Social Forces, 88(3), 1123-1151. doi:10.1353/sof.0.0295

Comenzó la guerra por la TV satelital (11 de junio, 1998). La Nación. Recuperado de http://www. lanacion.com.ar/99587-comenzo-la-guerra-por-la-tv-satelital

Corbalán, A. (2002). El Banco Mundial: intervención y disciplinamiento: el caso argentino, enseñanzas para América Latina. Buenos Aires: Editorial Biblos.

DEERE, C. (2009). The implementation game: the TRIPS agreement and the global politics of intellectual property reform in developing countries. Oxford: Oxford University Press.

Domínguez, N. (2013). El gran salto del tigre. Boletín del Centro Naval, 835, 37-47.

El Estado, a punto de controlar todo el negocio satelital argentino (23 de octubre, 2006). El Cronista. Recuperado dehttps://www.cronista.com/impresageneral/El-Estado-a-punto-de-controlartodo-el-negocio-satelital-argentino-20061024-0063.html

El Estado le quitó a Nahuelsat la asignación para Nahuel II (17 de agosto, 2004). Recuperado de https://www.cronista.com/impresageneral/Boletin-Oficial-El-Estado-le-quito-a-Nahuelsat-laasignacion-para-Nahuel-II- $\backslash /$-20040818-0100.html

El Gobierno ya asignó 50 millones a Arsat (7 de junio, 2006). El Cronista. Recuperado de http:// www.cronista.com/impresageneral/El-Gobierno-ya-asigno-los-50-millones-de-Arsat-200606080060.html

El Nahuel II buscaría ayuda económica a través de la Bolsa (6 de abril, 2004). Recuperado de http://www.infobae.com

En enero habrá conexiones con el satélite Nahuel (15 de diciembre, 1996). Clarín Digital. Recuperado de http://edant.clarin.com/diario/96/12/15/o-02701d.htm

EscudÉ, C. (1992). Realismo periférico: fundamentos para la nueva política exterior argentina. Buenos Aires: Planeta.

Etzkowitz, H., Levitt, J. y Gulbrandsen, M. (2000). Public venture capital: Government funding sources for technology entrepreneurs. Nueva York: Harcourt.

Evans, P. (1979). Dependent development: the alliance of multinational, state, and local capital in Brazil. Princeton, New Jersey: Princeton U.P.

Evans, P. (1985). Transnational linkages and the economic role of the state: An analysis of developing and industrialized nations in the Post-World War II Period. En P. Evans, D. RuescheMEYER y T. SKocPol (Eds.), Bringing the state back in (pp. 192-226). Cambridge: Cambridge University Press.

Foley, T. (1999). Latin America: The competitors line up. Recuperado de http://www.satellitetoday. com

GagGero, A. (2016). Las transformaciones de la elite empresarial en un periodo de extranjerización económica: los propietarios de los grandes grupos empresariales argentinos durante los años noventa. En A. Castellani y L. Cobe (eds.), Radiografía de la elite económica argentina: estructura y organización en los años noventa (pp. 89-122). San Martín: Universidad Nacional de San Martín. 
Godoy, R. (2017). Bloque PJ-Frente para la victoria. En Jefatura de Gabinete de Ministros. En Informe $N^{\circ}$ 100. Honorable Senado de la Nación (pp. 810-854). Buenos Aires: Presidencia de la Nación.

HARTLEY, K. (2014). The political economy of aerospace industries: a key driver of growth and international competitiveness? Cheltenham: Edward Elgar.

Hurtado, D. (2010). La ciencia en la Argentina: un proyecto inconcluso, 1930-2000. Buenos Aires: Edhasa.

Hurtado, D. (21 de julio, 2017). Hughes, ¿socio estratégico de quién? Recuperado de https://www. pagina12.com.ar/51478-hughes-socio-estrategico-de-quien

Hurtado, D., Bianchi, M. y LaWler, D. (2017). Tecnología, políticas de Estado y modelo de país: el caso Arsat, los satélites geoestacionarios versus "los cielos abiertos". Epistemología e Historia de la Ciencia, 2(1), 48-71.

Kirchner creará por ley la empresa nacional de satélites (4 de julio, 2005). El Cronista. Recuperado de https://www.cronista.com/

Krakowiak, F. (22 de agosto, 2016). Efecto pinzas sobre la estatal Arsat. Recuperado de https: //www.pagina12.com.ar

Kulfas, M. (2016). Los tres kirchnerismos: una historia de la economía argentina. Buenos Aires: Siglo Veintiuno Editores.

Lam, H.-L., Boteler, D. H., Burlton, B. y Evans, J. (2012). Anik-E1 and E2 satellite failures of January 1994 revisited: ANIK-E1 AND E2 SATELLITE FAILURES. Space Weather, 10, S10003. DOI: 10.1029/2012SW000811

LEE, K. (1996). Global telecommunications regulation: a political economy perspective. Londres: Pinter.

Martin, D. H., Anderson, P. R. y Bartamian, L. (2007). Communication satellites (5 ed.). Reston: The Aerospace Press/American Institute of Aeronautics and Astronautics.

Martin, W. G. (1990). Semiperipheral states in the world-economy. Nueva York: Greenwood Press.

McCormick, P. K. (2013). Neo-liberalism: A contextual framework for assessing the privatisation of intergovernmental satellite organisations. En P. K. McCormick у M. J. Меснаnick (eds.), The transformation of intergovernmental satellite organisations: policy and legal perspectives. Leiden: Nijhoff.

Méndez, L. (3 de febrero, 1997). Ya se trabaja en el Nahuel II. La Nación. Recuperado de http: //www.lanacion.com.ar

Michalski, W. (1991). Support policies for strategic industries: An introduction to the main issues. En Organization for Economic Co-operation and Development (ed.), Strategic industries in global economies. Policy issues for the 1990s (pp. 7-14). París: OECD International Futures Programme.

Nahuel 1 será lanzado en enero (19 de diciembre, 1996). La Nación. Recuperado de http://www. lanacion.com.ar/170694

Nahuelsat quiere participar en el proyecto satelital del Gobierno (27 de abril, 2006). El Cronista. Recuperado de http://www.cronista.com/impresageneral/Nahuelsat-quiere-participar-en-elproyecto-satelital-del-Gobierno-20060428-0037.html

NguYEn, T. T. (2010). Competition law, technology transfer and the TRIPS agreement: implications for developing countries. Cheltenham: Edward Elgar.

Oyarzábal, X. (1997). Argentine space assets (Tesis doctoral). Postgraduate Naval School, Monterrey, California, EUA. 
P. P. Sat 1 occupies $81^{\circ}$ west orbital position (19 de octubre, 2005). Convergencia Latina. Recuperado de http://www.convergencialatina.com/News-Detail/71306-3-51

Pekín también será parte del satélite argentino (1 de septiembre, 2004). El Cronista. Recuperado de https://www.cronista.com/

Pelton, J. N., Oslund, R, y Marshall, P. (eds.). (2004). Communications satellites: global change agents. Mahwah: Lawrence Erlbaum.

Puja con el Reino Unido por el segundo satélite argentino (23 de febrero, 2006). El Cronista. Recuperado de http://www.cronista.com/impresageneral/Puja-con-el-Reino-Unido-por-elsegundo-satelite-argentino-20060224-0030.html

Quieren saber cómo se cumple la guía de contenidos (2002). Recuperado de http://www.rt-a. com/69/20-69.htm\#2

Salzer examina el desembarco satelital argentino en Norteamérica (1999). Recuperado de http: //www.rt-a.com/34/SAT.html

Satellite unit of GE capital is being sold (29 de marzo, 2001). New York Times. Recuperado de http://www.nytimes.com

SCHILlER, D. (1999). Digital capitalism: networking the global market system. Cambridge: MIT Press.

Schober, E. (1996). Nahuel. The regional satellite system for the Americas. Recuperado de Connect World

Se mantiene una inversión (20 de marzo, 2002). La Nación. Recuperado de https://www.lanacion. com.ar/382203-que-pasa

SES Global finalise l'acquisition de GE Americom pour 4.3 milliards de USD et devient le numéro un des opérateurs de satellites mondiaux (12 de noviembre, 2001). Recuperado de http:// paperjam.lu/communique-de-presse

The new Latin American gold rush. (direct-to-home satellite business) (1 de mayo, 1995). Recuperado de https://www.highbeam.com/doc/1G1-17197986.html

Tycz, T. (23 de marzo, 2000). Williams Communications, Inc. Application for modification of Earth Station License W4 Communications Corp. (No. Order, DA 00-0663). US Federal Communications Commission.

Tycz, T. (12 de octubre, 2000). GE American communications, INC. Application for authority to launch and operate a replacement $C$-Ku hybrid fixed satellite service space station at $72^{\circ} \mathrm{W}$. (No. L. Memorandum Opinion, Order and Authorization, DA 00-2305). US Federal Communications Commission.

United States Department of Commerce (1995). Argentina-Telecom. Equip. and Services. International Trade Administration, Market Research Reports.

United States Department of State (1998). Agreement between the Government of the United States of America and Argentina (No. Treaties and Other International Acts Series, 12960). Recuperado de http://www.state.gov/documents/organization/112469.pdf

U.S. Firms Target Argentine Telecoms (octubre 14, 1997). Wall Street Journal, p. A16.

Vido, J. De y Bernal, F. (2015). Néstor y Cristina Kirchner. Planificación y federalismo en acción. Buenos Aires: Planeta.

YÜLEK, M. Â. (2012). Public expenditures on machinery and equipment in developing countries: A potential driver of technological development and industrialization. En M. Â. YüLEK y T. K. TAYLOR (eds.), Designing public procurement policy in developing countries: how to foster technology transfer and industrialization in the global economy (pp. 2-13). Nueva York: Springer. 
ZícARI, J. (2017). Del colapso de la convertibilidad a las bases económicas de la recuperación. En A. R. Pucciarelli y A. G. Castellani (eds.), Los años del kirchnerismo: la disputa hegemónica tras la crisis del orden neoliberal (pp. 35-60). Ciudad Autónoma de Buenos Aires: Siglo XXI Editores. 